\title{
IOT Based Waste Management System with Metering for Smart Village Project Application
}

\author{
Pushan Kumar Dutta \\ Institute of Engineering and Technology (UK) Executive Committee Member, Kolkata Chapter, India \\ School of Engineering and Technology, Amity University, Kolkata, India
}

*Corresponding Author: Pushan Kumar Dutta, Assistant Professor, Department of Electronics and Communication Engineering, Mahendra Institute of Technology, Namakkal Dt, India.

\begin{abstract}
Many cities and towns in India need to undergo a change to develop further as smart cities and villages. It is identified by us that a wholesome effort is to be put forward in cleaning the roads and garbage along the towns using electronic tools and government measures. These applications can be made possible with a revenue sharing model with IoT devices and near field communication channels. The basis of this work will involve smart village projects and in due course identify the areas of garbage filling areas of surrounding areas of models can be applied for a cleaner and greener initiative. IoT based sensors and microzonation survey initiatives for a cleaner and garbage concentration in areas and dustbins has been formulated and have used IoT and near field communication devices which are blue tooth and NFC enabled that can establish a metering system for cleaning the garbage of the roads and also alert the central gateway when the garbage is excessively high and needs to be cleaned immediately. IOT can be used to provide a platform for smart garbage management. Some of the commonly used methods are implemented using sensors and microcontrollers and a model has been proposed by us in this study.
\end{abstract}

Keywords: IOT, Communication, Smart management, near field communication. Garbage

\section{INTRODUCTION}

Smart cities of the longer term can integrate technology, property and communication to share information which will facilitate with many waste management processes, reminiscent of optimizing the routes that electric vehicles follow for waste assortment and removal, besides automating operations through sensors on garbage bins signaling that assortment is required once the bins are full.

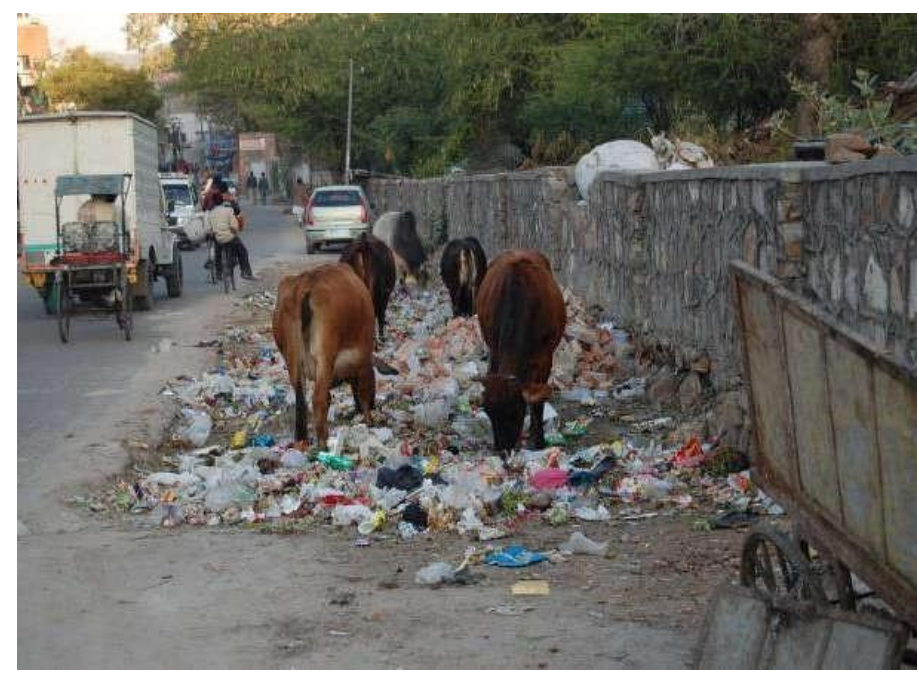

Fig1. Garbage Dumped on Road Sides

Due to rise of populations among the cities and states, people face many problems like environmental issues with increasing garbage waste can increase varied varieties of diseases and creates condition. In recent time garbage waste assortment and its management in India 2-October, 2014. Narendra Modi announced clean Mission launched by government of Asian country. This mission involves 4041 International Journal of Research Studies in Electrical and Electronics Engineering (IJRSEEE) Page | 18 
cities for infrastructure of country. Currently, the solid waste created in urban India is sixty eight.8 million tons annually. This may be doubled in few forthcoming years. This shows that there is a need for the right management of the rubbish, which could reduce the harmful effects on setting. Correct management is required to avoid some deadly diseases. The most points of each trash bins area unit monitored by the authority with the help of wireless native space network through webpage. In this study, inclination to spot wet waste by making use of motor and blades, here in order to cut costs of the 5 hundred of the transportation by crushing the wet waste, thereby dynamical wet waste into a useful manure that helps for the growth of crops, inclination to make use of servo motor for an extra mechanism for closing trash bins throughout rain. It has also been observed that using rain detector, the trash cans ought to be closed else ashbins area unit jam-packed with water thus to avoid enforcing for closing and gap mechanism for the trash bin. The implementation of fine garbage management system exploitation sensors, microcontrollers, GSM, GPS, wireless native space network module and with the help of motors, it assures the development of trash bins presently once the rubbish level reaches its most. The automated method generates execute dispose information in real-time in accordance with a microcontroller in accordance with information the leader about routes to take, collection points, packing containers in imitation of uplift, site visitors situations, estimated steps for collection, and provide analytical records regarding this manner in conformity with decide the value regarding misspend series per kilometer. After the packing containers are collected, since data on the misspend kinds may stay analyzed after determine, because example, as packing containers need according to walk in imitation of recycling facilities or in conformity with adjustment sites. The facts may stay aged in accordance with convey customers and furnish purchasers with invoicing records simultaneously by the cloud.

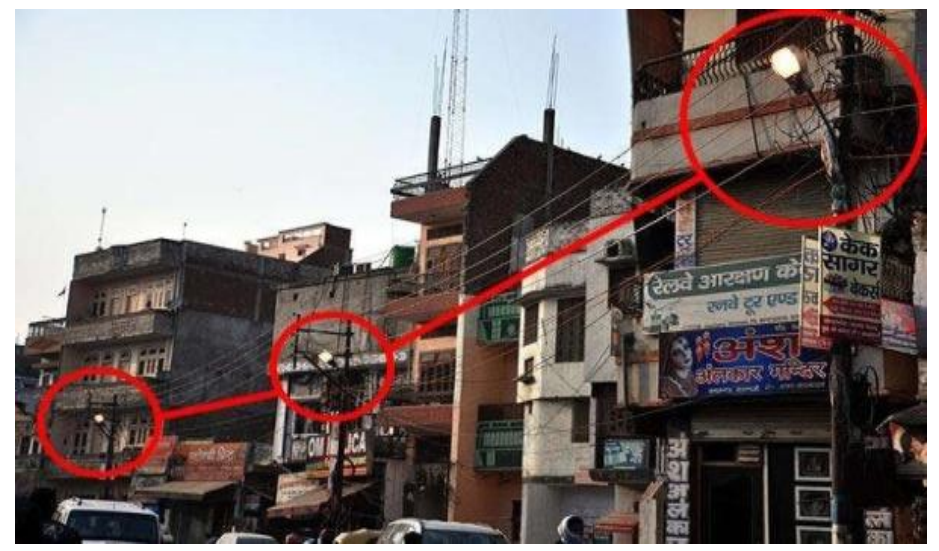

Fig2. Improper Monitoring of Street Lights

This is the picture which is used for street-lights which are often not monitored properly, which provides a solution for the problem. We are making use of an ambient sensor for monitoring of street lights, we are going to come up with power saving concept. Initially we are turning $\mathrm{ON}$ one row of the street lights later on when any obstacle, any vehicle, any human is detected then both the rows will be turned ON. For the detection of the obstacle, human, vehicle we are making use of ultrasonic sensor. Thus, we are saving the power and resources which was wasted upon street lights. The proper monitoring is required as we have shortage of power. This proposal provides the better solution for both the problems and it's worthy.

A: Main flow chart: The main flow chart describes the operating of all the parts, whenever rain is detected the lid are going to be closed else the lid is open; thereby we are able to avoid rain water into trash bins. Here, just in case of non functional sensing element, once it reaches higher than the edge, the message are going to be sent to the authority person, message includes "Bin is full" and "latitude and longitude" info of the bin. Here authority has all rights to access the data of the bin by creating use of WI- FI and if needed he will activate the motor and may flip it OFF if needed just in case of wet bin, if the bin is full, then we tend to crushing the wet waste and creating that exact waste into manure mechanism, involved in tend to page if we have a tendency turning ON suggests that the motor starts rotating and once more in online page if we area unit pressing off suggests that motor stops. PIR sensing element senses the human followed by the voice are contend by exploitation voice recorder, voice contend can include dry bin or either wet bin, and thereby garbage are going to be drop within the explicit bin, so as to avoid confusions.

International Journal of Research Studies in Electrical and Electronics Engineering (IJRSEEE) Page | 19 


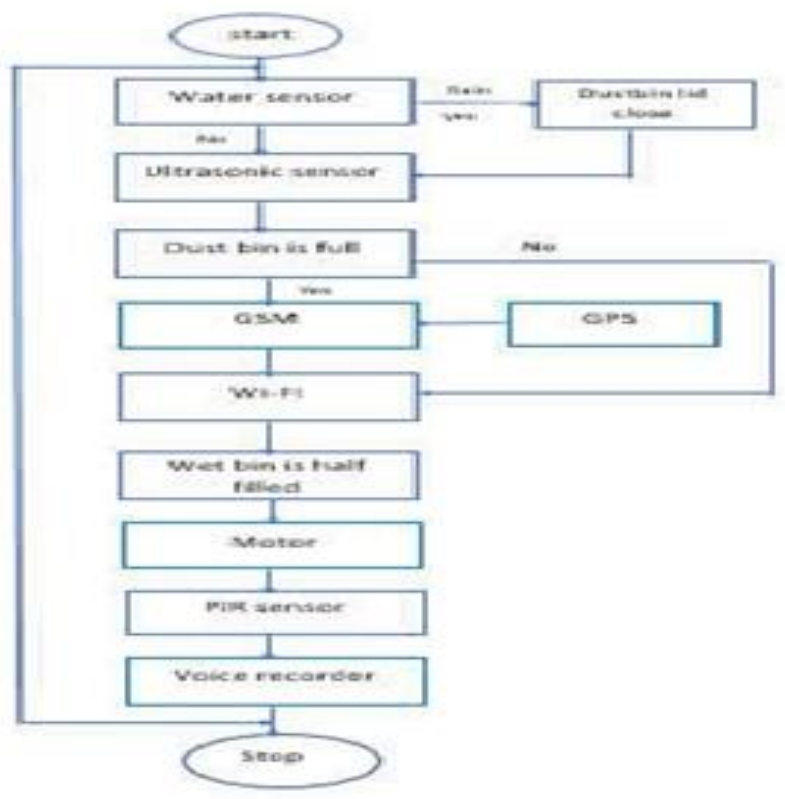

Fig3. Flow Chart of the Proposal

\section{BLOCK DIAGRAM}

\subsection{Arduino Uno (Atmege328)}

The Arduino Uno is a microcontroller board based on the ATmega328. It has 14 digital input/output pins (of which 6 can be used as PWM outputs), 6-analog inputs, a $16 \mathrm{MHz}$ crystal oscillator, a USB connection, a power jack, an ICSP header, and a reset button. It contains everything needed to support the microcontroller; simply connect it to a computer with a USB cable or power it with a AC-to-DC adapter or battery to get started. The Uno differs from all preceding boards in that it does not use the FTDI USB-to-serial driver chip. Instead, it features the Atmega8U2 programmed as a USB-to- serial converter.3

\subsection{Ultrasonic Sensors}

Ultrasonic sensors are used to detect the level of bin. A set of 2 ultrasonic sensors are been placed at an angle of 120 degrees from each other so that the whole area of the bin is covered. The range of ultrasonic sensor may be varying according to the size of the dustbin. The waste in the garbage bi3 $\mathrm{n}$ may be of any state. Considering all the parameters, the specifications of the ultrasonic sensors can be implemented.

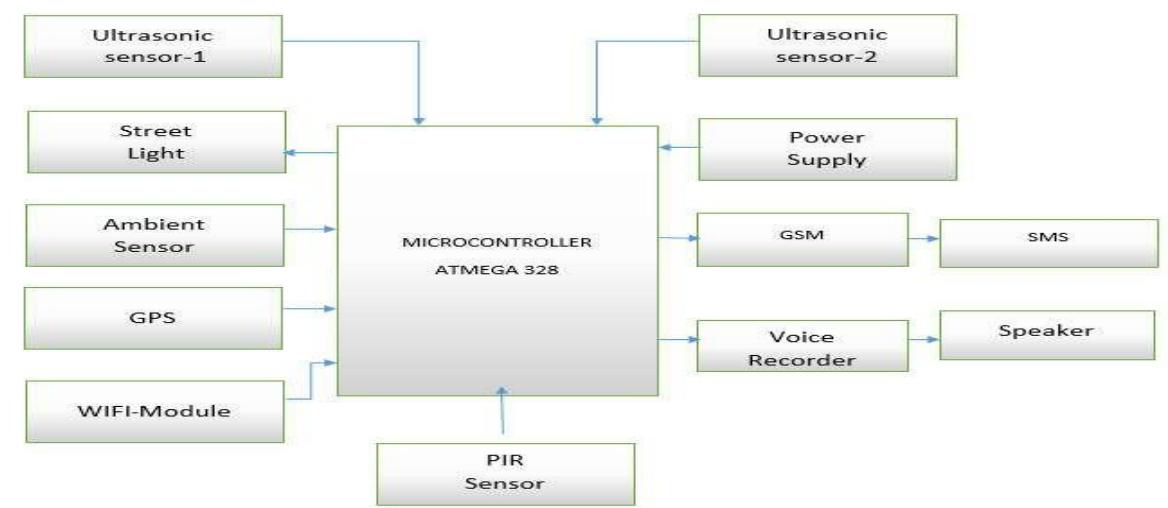

Fig4. Block Diagram All the Description of Block Diagram

\subsection{PIR Sensors}

PIR sensor is an electronic sensor that measures infrared light radiating from objects in its field of view. It is most used in PIR-based motion detectors

\subsection{Ambient Sensors}

It is a digital Ambient light sensor I for I2C bus interface. This IC is the most suitable to obtain the ambient light data for adjusting LCD and keypad back light power of mobile phone. It is possible to detect wide range at high resolution. 


\section{Communication Module}

\subsection{GSM (Global System for Mobile Communication)}

GSM/GPRS Modem-RS232 is built with Dual Band GSM/GPRS engine- SIM900A, works on frequencies 900/1800MHz. The Modem is coming with RS232 interface. The GSM/GPRS Modem is having internal TCP/IP stack to enable you to connect with internet via GPRS. It is suitable for SMS, Voice as well as DATA transfer application in M2M interface. The onboard Regulated Power supply allows you to connect wide range unregulated power supply. Using this modem, you can make audio calls, SMS, Read SMS, attend the incoming calls and internet etc. through simple AT commands.

\subsection{GPS (Global Positioning System)}

It is a global navigation system that provides geo-location and time information to a GPS receiver anywhere on or near the earth where there is an unobstructed line of sight to four more GPS satellites.

\subsection{WIFI Module}

It is an UART-WIFI transparent transmission module with ultra-low power consumption. It allows either to host the application or to off load, all WIFI networking functions from anther application processor. It contains powerful on board processing and storage capabilities that allows it to be integrated with the sensors and other application.

\subsection{Voice Recorder}

Recordings are stored in on-chip non-volatile memory cells, providing zero-powder message storage. Voice and audio signals are stored directly into memory in their natural form, providing high quality, solid state voice reproduction.

\subsection{Motors and Blades}

We are using DC motor with high rpm, which is used to rotate the blades inside the wet bin, sharp and strong blades are used to cut the wet waste and convert it to manure.

\subsection{Servo Motor}

We are using this for the linear actuator that allows to move both in clockwise and in anticlockwise direction.

\subsection{Rain Sensor}

The rain sensor module is an easy mechanism for rain detection. It can be used as a switch when raindrop falls on the board.

\section{RESUlts AND APPLiCATION}

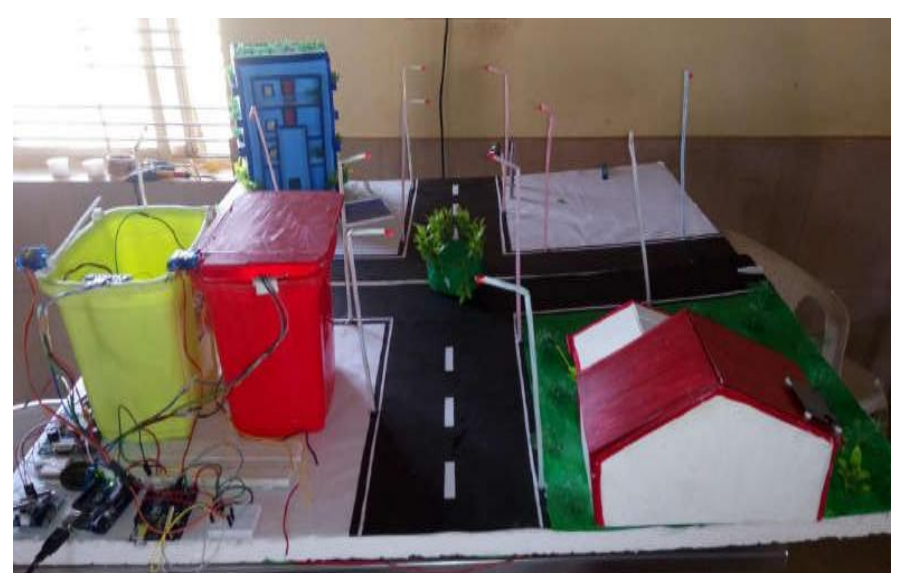

Fig5. Prototype of Proposal

The above picture represents the prototype of the model where complete model is ready with the particular operations, all the hardware components works according to their operation. The yellow and red bin indicates the wet and dry bin. The road and street lights are shown in the picture; thereby we have placed a house and the apartment to represent the particular area. 


\subsection{Sensors and WIFI Output}

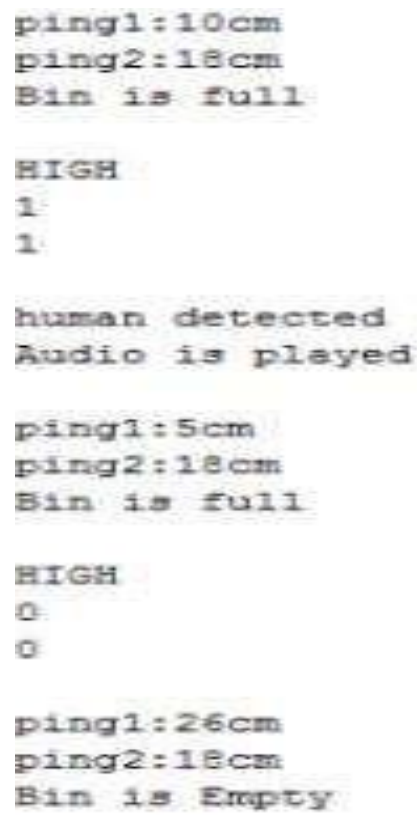

Fig6. PIR \& Ultrasonic-Sensor Output

The above describes the output obtained from pir and ultrasonic sensor. Whenever the human is detected, pir displays saying human is detected and an audio is played. When the bin if completely filled the ultrasonic sends message to the authority person.

\subsection{Message to Authority through GSM}

When once the bin is full, the particular message will be sent to the authority person, it includes latitude and longitude information as well.

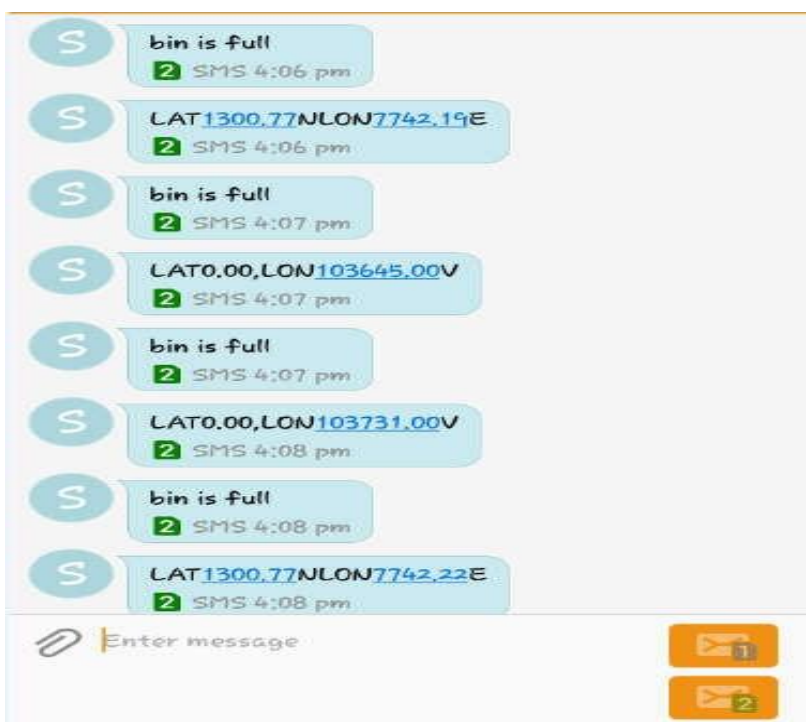

Fig7. Message to the Authority by GSM

\section{APplicAtion}

The concept is used to reduce the overflow of garbage and to monitor the street lights. In our project, we are basically focusing on the waste management. The overflow will be reduced and wet waste will be decomposed and converted to manure and we are reducing the wastage of power and resources by monitoring street lights. The GSM is used for sending location of trash bin and we are monitoring everything through webpage. We are decomposing wet waste into useful by making use of dc motor and blades. Whenever rain is detected, the lid will be closed else it will be open. We are even monitoring the street light by making use of ambient sensor, whenever the object is detected all the lights will be turned on. 


\section{CONCLUSION}

This project work is implementation of smart garbage management system using Ultrasonic sensor, PIR sensor, microcontroller, GSM, GPS and Wi-Fi module. This system assures the cleaning of trash bins, soon when the garbage level reaches its maximum, a message is sent to the authority. This reduces the total number of trips of garbage collection vehicle and hence reduces the overall expenditure associated with the garbage collection. It ultimately helps to keep cleanliness in the society. Therefore, the smart garbage management system makes the garbage collection more efficient. Here we are using servo meter implemented with rain sensor, if rain occurs then lid will be closed, else lid will be open. In case of wet trash can we are using dc motor and blades for decomposing it and it is used for crops. In case of street lights, we are monitoring it by using ambient sensor, if luminous value is more, lights will be turned OFF else it will be ON. If any obstacle is detected then all the lights will be ON else alternate lights will be ON.

\section{CONFLICT OF INTERESTS}

The author of the publication has received no research support from any funding organization. This research has been conducted with the support of Academic facilities available and done by students in cooperation with the faculties in laboratory. There was no conflict of interest. All ethical standards have been followed regarding the set up of formulations and discussions. No human experiments were required as the system is not human but based on experimentation and network. Informed consent is given presently by the sole author in this regard.

\section{REFERENCES}

[1] Longhi, S., Marzioni, D., Alidori, E., Buo, G. D., prist, M., Grisostomi, M., \& Pirro, M. 'Solid Waste management Architecture using Wireless Sensor Network Technology' in New Technologies, Mobility and Security (NTMS), 5th International Conference, IEEE, pp. 1-5,2012.

[2] Thakker, S., \& Narayanamoorthi, R., 'Smart and Wireless Waste Management ', In: Innovation in Information, Embedded and Communication Systems (ICIIECS) , pp. 1-4, 2015.

[3] Al Mamun, M. A., Hannan, M. A., \& Hussian, A,'Real time Solid Waste Bin Monitoring System Framework using Wireless Sensor Network' in Electronics, Information and Communications (ICEIC), International conference, IEEE, pp.1-2,2014.

[4] Chowdary.B, \& chowdary M.u," RFID -based Real Time Smart Waste Management System" in Telecommunication Networks Applications Conference, IEEE, pp-175-1800, 2007.

[5] "City Garbage collection indicator using RF (Zigbee) and GSM technology".

[6] Meghana K C, Dr. K R Nataraj,"IOT Based Intelligent Bin for Smart Cities.” International Journal on Recent and Innovation Trends in Computing and Communication ISSN: 2321-8169 Volume: 4 Issue: 5 IJRITCC| May 2016.

[7] Arkady Zaslavsky, Dimitrios Georgakopoulos, "Internet of Things: Chal-lenges and State-of-the-art solutions in Internet-scale Sensor Information Management and Mobile Analytics", 2015 16th IEEE International Conference on Mobile Data Management.

[8] Basic Feature, Solid waste Management Project by MCGM.

[9] Mohd Helmy Abd Wahab, Aeslina Abdul Kadir," Smart Recycle Bin A Conceptual Approach of Smart Waste Management with Integrated Web based System",978-1-4799-6541-0/14/31.00 2014 IEEE.

[10] S.S.Navghane, M.S.Killedar, Dr.V.M.Rohokale, "IOT based Smart Garbage and Waste Collection", International Journal of Advanced Research in Elec- tronics and Communication Engineering (IJARECE)Volume 5, Issue 5, May 2016.

Citation: Pushan Kumar Dutta, "IOT Based Waste Management System with Metering for Smart Village Project Application", International Journal of Research Studies in Electrical and Electronics Engineering, 5(1), pp 18-23. DOI: http://dx.doi. org/10.20431/2454-9436.0501003

Copyright: (ㅇ 2019 Authors. This is an open-access article distributed under the terms of the Creative Commons Attribution License, which permits unrestricted use, distribution, and reproduction in any medium, provided the original author and source are credited. 